\title{
Delivery of MDT through blister calendar packs in leprosy eradication programmes- a multicentre field study (Phase I)
}

\author{
C R REVANKAR, BIRTE H SORENSEN, \\ R W KIELSTR UP* and Multicentre Study \\ Group $\dagger$ \\ DANID A-D ANLEP, 7 Golf Links Area, New Delhi 110 003, India; \\ *Pharmanova AS, PO Box 10, 25 Industriparken, DK 2750 \\ Ballerup, Copenhagen, Denmark
}

\section{Accepted for publication 23 February 1989}

\begin{abstract}
Summary To overcome operational problems and improve patient compliance in leprosy programmes, DANIDA introduced blister calendar packs (BCP) to deliver MDT in four districts in India. A questionnaire study of 1470 patients from these districts showed that more than $90 \%$ accepted BCP and found them to be very convenient for domiciliary treatment. A similar study of 127 treatment providers indicated that delivery of MDT through BCP was found convenient to overcome logistic problems.
\end{abstract}

\section{Introduction}

One of the important factors for the success of the MDT programme is to obtain maximum compliance for pulse doses as well as for self-administered doses. Compliance is influenced by many factors. Of relevance here are a continuous and regular supply of all the three drugs and simple methods of preserving these drugs at the patients' houses without damage or loss. As the disease is still associated with social stigma, making drug delivery in a socially acceptable attractive form is an additional factor which influences patients' compliance. Other operational factors like easy storage, easy transportation without any loss or damage, easy accounting and preparation for clinics at control unit level could also affect the efficiency of the MDT programme in general.

To overcome operational problems in the field, delivery of antileprosy drugs through BCP similar to oral contraceptives was conceptualized as early as $1983 .{ }^{1}$ Ciba-Geigy Basle (1986) designed and manufactured BCP following a WHO recommendation on MDT for multi- and paucibacillary forms of leprosy. ${ }^{2}$

DANIDA is assisting the National Leprosy Eradication Programme (NLEP) in India in four districts (Cuttack in Orissa, Salem in Tamil Nadu, Durg \& Rajnandgaon in Madhya Pradesh). As an alternative strategy of drug delivery, it was decided to use BCP for an estimated 160,000 patients (MB 40,000 and PB 120,000) with the following objectives:

$\dagger$ R N Acharya, S Biswal, N Binayak, S L Gude, S L Gupta, P R Mangalani, G P Mishra, N Murugesan, T D Pandian, S B Patnaik, M R Prusthy, T N Swaminathan, B L Sharma, S Raye, S N Satpathy and A A Swamy. 
Improved drug supply:

Safe-no pilfering, no spoilage.

Effective-right drug regimen is given.

Efficient - easy drug delivery.

Improved patient compliance:

Safe-self-protected, easy storage at patient's house.

Regular-self-monitoring possible.

\section{Increased cost-effectiveness:}

Pharmanova, Copenhagen designed and manufactured these packets for MB-adults (red colour), PB-adults (green colour) and PB-children 6-14 years (blue colour) suitable for the Indian MDT programme. ${ }^{3}$ As no published reports are yet available on evaluation of this alternative approach in improving operational efficiency of the programme, DANIDA decided to undertake a multicentre field study to find out: (a) feasibility of using BCP in the vertical leprosy programme; (b) influence of these packed drugs on patients and field staff; and (c) cost-effectiveness of using blister packs.

In this paper results of Phase I of the study are reported.

\section{Material and methods}

This multicentre study was designed in two phases:

Phase I. A structured questionnaire study was designed to obtain subjective impressions of patients and staff regarding the acceptance and use of $\mathrm{BCP}$ in a routine MDT programme.

Phase II. A study of patient compliance comparing patients receiving blister packs with patients in the same district receiving bulk drugs.

\section{METHODOLOGY FOR PHASE I STUDY}

1 Under NLEP-India, MDT is being delivered through a circuit plan (a circuit consists of 2 subcentres of 2 paramedical workers with approximately 40,000 population). ${ }^{4}$

2 Subcentres which had completed a minimum of 6 months' treatment with $\mathrm{BCP}$ were selected randomly.

3 At the time of this study a total of 48,000 patients were given BCP in all the four districts. A total of 10,000 patients had completed 6 months of MDT in 105 subcentres. Out of these, 57 subcentres were selected randomly and $1470(14 \%)$ adult patients were interviewed.

4 To overcome any bias, the interviews were conducted by volunteers not connected with the programme.

5 From the same subcentres 127 control unit staff were randomly selected for interview.

Table 1. Number of leprosy patients interviewed

\begin{tabular}{lrrrrrr}
\hline & \multicolumn{2}{c}{ Type } & & \multicolumn{2}{c}{ Sex } \\
\cline { 2 - 3 } \cline { 5 - 6 } No. of patients interviewed & MB & PB & & M & F \\
\hline 1470 & 615 & 855 & 947 & 523 \\
$\%$ & 42 & 58 & & 64 & 36 \\
\cline { 1 - 2 } & & & & & &
\end{tabular}


Table 2. Impressions of patients on blister calendar packs (BCP)

\begin{tabular}{|c|c|c|c|}
\hline \multicolumn{2}{|c|}{ Questions } & \multirow{2}{*}{$\begin{array}{c}\text { No. of patients with } \\
\text { positive answers } \\
1433\end{array}$} & \multirow{2}{*}{$\begin{array}{l}\% \\
97\end{array}$} \\
\hline 1 & $\mathrm{BCP}$ are attractive & & \\
\hline 2 & Preservation and handling are easy & 1449 & 99 \\
\hline 3 & Tablets could be taken out easily from BCP & 1446 & 98 \\
\hline 4 & Drugs are not spoiled & 1395 & 95 \\
\hline 5 & BCP helps patients to take drugs regularly & 1357 & 92 \\
\hline 6 & Drugs are taken regularly & 1362 & 93 \\
\hline 7 & Drugs are very effective & 1351 & 92 \\
\hline 8 & Printed numbers on BCP are not understood & 802 & 55 \\
\hline 9 & Instructions for preservation are not understood & 996 & 68 \\
\hline 10 & Last tablet reminds the patient of clinic day & 772 & 49 \\
\hline
\end{tabular}

Table 3. Impressions of staff on blister calendar packs (BCP)

\begin{tabular}{|c|c|c|c|}
\hline \multicolumn{2}{|c|}{ Questions } & \multirow{2}{*}{$\begin{array}{c}\text { No. of staff with } \\
\text { positive answers } \\
126\end{array}$} & \multirow{2}{*}{$\frac{\%}{99}$} \\
\hline 1 & $\mathrm{BCP}$ attractive & & \\
\hline 2 & Easy to handle, transport and preserve & 124 & 98 \\
\hline 3 & Attendance rate for pulse clinic increased & 113 & 89 \\
\hline 4 & Regularity for self-administered doses increased & 120 & 94 \\
\hline 5 & Tablet count shows correct self-administered dose & 108 & 85 \\
\hline 6 & Clof azimine capsules stick inside the pack & 74 & 58 \\
\hline 7 & Blister packs are not lost by the patients & 109 & 86 \\
\hline 8 & BCP suits the circuit plan and pulse clinic & 105 & 83 \\
\hline 9 & Drug accounting, dispensing and instructing patients easy with $\mathrm{BCP}$ & 101 & 79 \\
\hline \multirow[t]{3}{*}{10} & Time required for counting BCP for a clinic: & & \\
\hline & (a) less than 1 hour & 111 & 87 \\
\hline & (b) $1-3$ hours & 16 & 13 \\
\hline & Time required for counting and packing loose drugs for a clinic: & & \\
\hline & (a) $3-5$ hours & 84 & 66 \\
\hline & (b) more than 5 hours & 43 & 34 \\
\hline
\end{tabular}

\section{Results and discussion}

A total of 1470 were interviewed, $1213(83 \%)$ had treatment for 6-12 months and 257 (17\%) had more than 12 months treatment with blister calendar packs (Table 1).

1 These answers (Table 2) indicate that blister calendar packs were well accepted by the patients. They were attractive, could be preserved easily at home and drugs were not spoiled. Only $5 \%$ of patients reported that clof azimine capsules were sticking to the PVC and broke when removed. 2 More than $92 \%$ of the patients said that they were taking drugs regularly. More than $50 \%$ of the patients were not able to read the numbers and instructions written on the BCP. This indicates that there is further scope for improving the design of BCP. Perhaps their sequence could be given in pictorial form, i.e. showing arrow marks for directions, symbolic presentations for days, etc. Only $392(27 \%)$ said that they could understand instructions written in English.

3 Of the patients $92 \%$ said that these drugs were very effective. This impression could be due to the attractive exterior of $\mathrm{BCP}$.

The answers (Table 3) indicate that the staff of leprosy control units from all these four districts found that the BCP were attractive, easy to deliver and that less time was used in preparing for 
clinics compared with using bulk drugs. This was based on their experience during the first 14 days of intensive therapy where all the drugs were delivered loose. The subjective impression of the staff on the increase in regularity is to be confirmed by an objective study which is in progress.

This preliminary study has shown that $\mathrm{BCP}$ were accepted both by the leprosy patients and the staff. The BCP design was suitable for the MDT programme and facilitated delivery of the right drugs by the colour of the packs. Drug accounting, storage and transportation was also found to be easier. These findings support our initial observations reported earlier. ${ }^{5}$

One reservation about the use of $\mathrm{BCP}$ on a mass scale would be the additional cost over bulk drugs. However, once economies of scale are achieved in the production of $\mathrm{BCP}$, it is believed that the price differential will probably be no more than $15 \%$.

\section{Acknowledgments}

The authors are thankful to the Government of India and the State Health Authorities for permitting DANIDA to deliver MDT through blister calendar packs. The authors are also thankful to Mr S Sriram for secretarial assistance and Mrs Nivedita Gupta for computer analysis.

\section{References}

1 Winsley BE, McDougall AC Browne KE. Chemotherapy of leprosy: 'bubble' or 'calendar' packs for administration of rifampicin, dapsone, clofazimine or prothionamide/ethionamide. Int J Lepr, 1983; 51: $592-4$.

2 Ciba-Geigy. Bubble or calendar packs for multiple drug therapy in leprosy. Lepr Rev, 1986; 57: 181-2.

3 Georgiev GD Kielstrup RW. Blister calendar packs for the implementation of multiple drug therapy in DANIDA Assisted Leprosy Control Projects in India. Lepr Rev, 1987; 58: 249-55.

4 Government of India, Guidelines for Multidrug treatment in Endemic districts. Published by Leprosy Division, DGHS, New Delhi, 1986.

5 Revankar CR, Sorensen Birte H. Blister calendar packs for the treatment of patients in leprosy control programmes with multiple drug therapy. Letter to the Editor, Lepr Rev, 1988; 59: 84. 